\title{
Power and Agency in Conceptualizing Life Stages as Master Narratives
}

\author{
Commentary on Arnett
}

Moin Syed

University of Minnesota, Minneapolis, MN, USA

\author{
Keywords \\ Agency $\cdot$ Power $\cdot$ Life stages $\cdot$ Master narratives
}

Psychologists have a long history of engaging in simplistic debates that provide broad contours to the discipline (e.g., nature vs. nurture, universal vs. culture-specific processes). Such a debate has been central to developmental science since its inception: continuity versus discontinuity in development [Schulenberg, Maggs, \& O'Malley, 2003]. In other words, is development an incremental process consisting of many small changes that accumulate over time (i.e., continuous development)? Or does development follow a series of stages, wherein brief periods of dramatic change serve as transition points between periods of coherent stability (i.e., discontinuous development)?

What sometimes gets lost in these scholarly arguments is the phenomenology of real people, that is, what people actually believe and experience. From a folk psychological perspective, there is really no doubt that people understand life stages and use them to make sense of their own lives and the lives of others. This point seems to be clearly demonstrated in Arnett's analysis [this issue], through which he argues for both historical and contemporary cross-cultural prevalence of stages as a governing prescriptive framework for what a life through time ought to look like. Arnett refers to these stages as indigenous to make this very point, that these are stages "arising in the course of cultural life, as distinguished from the life stage theories proposed by academic psychologists" (p. 291). ${ }^{1}$ In this regard, Arnett takes a useful side-

1 It is worth noting that the term "folk life stages" may be preferable to "indigenous life stages" due to the fact that most conceptions of life stages in a given culture will be defined by those who hold social power, which is not necessarily the group who is indigenous to the region (especially in a colonization context).

\begin{tabular}{ll}
\hline KARGER & @ 2017 S. Karger AG, Basel \\
E-Mail karger@karger.com & $0018-716 X / 17 / 0595-0317 \$ 39.50 / 0$ \\
www.karger.com/hde &
\end{tabular}

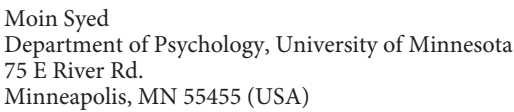


step around the scholarly argument about continuity versus discontinuity. That debate has almost no bearing on the notion of folk life stages if the researcher, clinician, or practitioner is primarily interested in individuals' conceptualization of the lifespan from their own perspective. And, indeed, this is most certainly an area of inquiry worth pursuing.

My thinking in this area [Syed, 2015; Syed \& McLean, 2015] has primarily been with respect to emerging adulthood as a life stage [Arnett, 2000, 2011], but that thinking has also been extended to the entirety of the lifespan. In the emerging adulthood literature there is a great deal of debate about whether emerging adulthood truly constitutes a life stage and the degree to which different members of society are represented by the concept, particularly those who occupy marginalized social positions (e.g., mostly in terms of social class, race, ethnicity, and nation). But as I have argued elsewhere [Syed, 2015; Syed \& Mitchell, 2013], this debate has been waylaid by a critical conflation of two distinct levels of analysis when it comes to understanding the psychology of life stages: the life stage itself as it is culturally defined (the sociological level) and the individuals who may (or may not) inhabit that life stage (the psychological level). The life stage of emerging adulthood provides a clear example of the importance of this distinction. Even if a given 20-year-old in the USA feels like an adult and otherwise exhibits the psychological and social characteristics of adulthood, she would be violating the broader cultural understanding of that life stage within society, and that violation would likely require some degree of management on her part. Given the presence of these two distinct levels of analysis, how should we go about studying them?

\section{The Generalizability of the Master Narrative Framework to Understand Self and Society}

This specific point about emerging adulthood can be generalized to other life stages - and, indeed, to other psychological phenomena more broadly - as a question of the interaction of individuals and societies. Building upon and refining past scholarship on the topic [Hammack, 2008; McAdams, 2006; Thorne \& McLean, 2003], Kate McLean and I recently articulated a master narrative framework [McLean \& Syed, 2015] to encourage a research agenda that fully examines the interaction of self and society. We define master narratives as "culturally shared stories that guide thoughts, beliefs, values, and behaviors" [McLean \& Syed, 2015, p. 323; see also Bamberg, 2004; Hammack, 2008, 2011; Thorne \& McLean, 2003]. Two core differentiating features of the master narrative framework in relation to other contextual theories are (a) a rejection of the notion of "top-down" influence of societal (cultural, contextual) factors on individual development in favor of processes of mutual interaction and embeddedness of individuals and societal factors, and (b) the recognition of the cultural constraints on individual agency to develop an identity and live a good life.

Master narratives are the "stuff" of society. They provide a template for understanding acceptable behaviors, thoughts, and attitudes within a given society. In outlining our master narrative framework we specified five principles of master narratives: utility, ubiquity, invisibility, compulsoriness, and rigidity [McLean \& Syed, 2015]. In brief, master narratives provide a social function of how one ought to be (utility); they are seen through many aspects of society, in family life, institutions, and 
the media (ubiquity); they are cast as natural, so they are rarely even noticed or named by those who align with them (invisibility); it is expected that most members of a society will adhere to them, and there are often real risks to deviating and endorsing an alternative narrative (compulsoriness); they gain their power from being resistant to change in order to maintain the current system (rigidity).

Furthermore, we specified that master narratives consist of three types: structural, which are the ways in which individuals tell stories (e.g., redemptive stories), episodic, which is how people narrate specific major life episodes (e.g., stories of the terrorist attacks on 9/11), and biographical, or narratives of lives through time. Arnett's discussion of life stages as master narratives clearly falls in this biographical type and is mostly consistent with our conceptualization. Indeed, it has long been known that there are biographical markers along the lifespan that people can readily point to when defining a good and normative life [Habermas \& Reese, 2015; Neugarten, 1968; Rubin \& Berntsen, 2003]. Arnett helps push forward these ideas in a broader context by elaborating on how they can be situated within the master narrative framework. Doing so generates new and interesting questions.

Indeed, a master narrative approach to life stages renders the question of whether or not any individual person is an emerging adult to be an incomplete question that results in an incomplete answer. This way of thinking moves away from the debate on continuity versus discontinuity to one about how individuals interact with the culture-specific discontinuities around them. From this framing we can ask questions such as how a person aligns with the normative expectations of that point in the life course, and the degree to which this alignment (or lack thereof) creates short- and long-term stress. In short, how do individuals personally navigate these master narratives of life stages? In this way, such a conceptualization is not so different from research on puberty. Rather than attempting to solely determine individuals' pubertal status (i.e., how they have progressed through maturational processes), to fully understand the psychological aspects of puberty one must also assess how individuals align with the normative pubertal process in that cultural (pubertal timing) and how quickly they move through the pubertal process (pubertal tempo [Natsuaki, Samuels, \& Leve, 2015]). Indeed, given that puberty lies at the fulcrum of many folk theories of the transition from childhood to adolescence, we would do well to better incorporate such research in broader conceptualizations of life stages as master narratives.

This latter point illustrates that there already exists a great deal of research that is relevant to life stages as master narratives. However, the vast majority of it has not been wrangled into the broader master narrative framework. That is what the master narrative framework allows - a broader understanding of lives through time as situated in multiple contexts - and I hope to see more work that mirrors Arnett's approach in other domains (e.g., schooling) as well as work that takes Arnett's ideas even deeper. As luck would have it, I have some thoughts about that.

\section{A Point of Departure: A Master Narrative without the Power and Constraints May Not Be a Master Narrative after All}

While I applaud and encourage the framing of life stages within a master narrative framework, it is also important to recognize that Arnett's synthesis of life stages and master narratives is incomplete. In particular, his analysis lacks a proper consid- 
eration of power and agency - a consideration that is central to the master narrative framework. Master narratives are cultural tools used to maintain social order, and thus those who possess greater societal power are more likely to align with and reinforce them. The master narratives of life stages are presented somewhat neutrally in Arnett's paper. To be sure, Arnett's discussion of alternative narratives and how some might not fit with the master narrative provides acknowledgement of the risks and challenges involved in deviating from the master narrative. But it still lacks a sufficient analysis of the societal power that underlies master narratives.

Making power central to the conceptualization of master narratives is, in part, what sets master narratives apart from the extensive research on life scripts and biographical markers of development. Life scripts have the same prescriptive, normative flavor of master narratives, but the concept of life scripts does not inherently involve the questions of who the creators of the scripts are, for what purpose they were developed, and what purpose they serve. These are critical - dare I say necessary - questions when adopting a master narrative perspective.

A fundamental question when thinking about life stages as master narratives is whose lives are being represented [see also Cole, 2009, for the relevance of this question to intersectionality]. Examining both Arnett's historical and anthropological analysis indicates that it is clearly the life course of men that tends to define the life course, particularly of men with institutional power. Even when women are represented, they are included in relation to men or otherwise to assist with furthering the development of men. The life stages are not defined in terms of women's own developmental experiences and goals. As we discussed when introducing our model, women have a more central biological reality with respect to childbirth that must be negotiated. This reality creates a strong tension between caring for children and engaging in work outside of the home. It is very likely that if the life stages were conceptualized around women's lives, work-life balance would be a central defining feature given their salience [Frisén, Carlsson, \& Wängqvist, 2014; Meeussen, Veldman, \& van Laar, 2016].

There is an important set of corollaries to the first question about whose lives are being represented: What are the implications for the lives of those who are not represented by the master narratives? How does the master narrative constrain their development? It is with these questions that we must consider individuals' agency in their own lives. The master narrative framework adopts a much more circumscribed notion of agency than is typical of research in identity, or even psychology more broadly [McLean \& Syed, 2015]. Given the core assumption that master narratives are largely unconsciously internalized by those who align with them, they can provide a false sense of agency. That is, individuals may appear to be forging their own, selfchosen life path, but aligning with the biographical master narrative reflects a process akin to identity foreclosure - a decidedly nonagentic identity structure [Carlsson, Wängqvist, \& Frisén, 2015].

The pressure for individuals to align with the master narrative is real and consequential. In the USA there is a powerful master narrative of the American Dream [Hochschild, 1996]. Fitting with the capitalist ethos of the USA, the American Dream defines success as material and social wealth. This success can be attained by following a prescribed sequence of life events - go to school, get a job, get married, buy a house, have children, and live happily ever after. The ideological underbelly of this normative sequence is that of self-sufficiency, that success comes about through 
hard work and determination. There is even an often propagated motto for this life course - the Land of Opportunity - a sure sign that a master narrative is at work. ${ }^{2}$

But whose dream is it? Who is able to attain it? Home ownership is a central aspect of the American Dream master narrative and is a status that many in the USA will make great sacrifices to achieve, such as long-distance work commutes and financial peril [Calder, 2009]. Indeed, it is not too far-fetched to think of the 2008 US housing crisis as being caused by the American Dream. So-called predatory lenders exploited individuals who were chasing the dream but had insufficient means - and they chased the American Dream right into foreclosure and financial ruin.

Indeed, as with gender, there are serious questions about how life stages function similarly across race/ethnicity, socioeconomic status, and their intersection. One of the core debates about emerging adulthood is regarding who "gets to be" an emerging adult. That is, while Arnett has argued that emerging adulthood generally applies as a life stage across race/ethnicity and socioeconomic status [Arnett, 2016], many critics have strongly disagreed, with each side providing different types of data to bolster their case [Côté, 2014; Furstenberg, 2016; Hendry \& Kloep, 2007; Silva, 2016]. Of course, pursuing the binary question of "emerging adult or not?" is a fool's task, as the reality is that individuals will fall along a spectrum, showing different degrees of emerging adulthood-ness in different domains of life and at different points in development [Mitchell \& Syed, 2015; Syed \& Mitchell, 2013].

I raise this point here because I find it interesting that this debate about the applicability of a life stage tends to be limited to emerging adulthood, and not extended to other portions of the lifespan. Adolescence - the life stage immediately preceding emerging adulthood - serves as a useful comparison. Some have argued that emerging adulthood is simply a euphemism for "college student," and that it is a luxurious psychological state not afforded to the "forgotten half," the approximately $50 \%$ of the US population that does not attend college [Hendry \& Kloep, 2007]. Thus, for many critics, educational context is a key indicator of inhabiting a life stage. So then, what about adolescence?

Recently the 2015 high school graduation rates for students in the USA were released to much acclaim, as the overall rate of $83.2 \%$ was a record high [National Center for Education Statistics, 2016]. While this is positive news, it of course also means that $16.8 \%$ of adolescents did not complete high school. This may not look so bad, but the overall average can mask important variations. For example, the overall graduation rate for Native Americans is much lower at $71.6 \%$, and is as low as $45 \%$ in the state of Wyoming. For students with disabilities the overall graduation rate is $64.6 \%$, with a low of $29 \%$ in Nevada. Nearly half of the 50 states in the USA have graduation rates lower than $75 \%$ for adolescents from economically disadvantaged backgrounds.

Should all of these millions of students, who at some point drop out of high school, still be considered adolescents? Are they included in our samples of adolescent research? Are their life experiences sufficiently reflected in our theories and models of adolescent development? Do we expect them to align with the life stage master narratives that are created and sustained by those who successfully move through the educational system? What shot do they have at the American Dream? Holding these questions to the fire is beyond the scope of this commentary, but I raise

2 See also the slogan "United We Stand" in the aftermath of 9/11 [Sontag, 2002].

Power and Agency in Life Stages 
them here because they are exactly the kind of questions that arise from a master narrative perspective. Conceptualizing human lives as the interaction among personal, master, and alternative narratives requires a full analysis of social power, inequality, opportunity, as well as the ways in which individual lives are constrained by master narratives.

\section{Conclusion}

A productive debate is crucial for moving a field of inquiry forward. In my view, Arnett's thinking has undoubtedly been stimulated by the controversies, challenges, and debates around the topic of emerging adulthood. There is a direct line from those debates to his conceptualization of life stages as master narratives. He has been forced to think more deeply about life stages, what they look like within and across cultures, and how to best conceptualize them. Elaborating on how life stages can serve as master narratives is a welcome contribution to the field, one that has the potential to stimulate new thinking and revisit the old. But in doing so, let's also be sure to keep power and the constraints of agency at the center of the model, and not pushed to the periphery.

\section{Acknowledgment}

Thanks to Kate McLean for reading over this commentary and ensuring that I was being coherent. Responsibility for all remaining incoherence, of course, lies with me alone.

\section{References}

Arnett, J.J. (2000). Emerging adulthood: A theory of development from the late teens through the twenties. American Psychologist, 55, 469-480. doi:10.1037/0003-066X.55.5.469

Arnett, J.J. (2011). Emerging adulthood(s): The cultural psychology of a new life stage. In L.A. Jensen (Ed.), Bridging cultural and developmental psychology: New syntheses in theory, research, and policy (pp. 255-275). New York, NY: Oxford University Press.

Arnett, J.J. (2016). Does emerging adulthood theory apply across social classes? National data on a persistent question. Emerging Adulthood, 4, 227-235. doi:10.1177/2167696815613000

Bamberg, M. (2004). Form and functions of "slut bashing" in male identity constructions in 15-year-olds. Human Development, 47, 331-353. doi:10.1159/000081036

Calder, L. (2009). Financing the American dream: a cultural history of consumer credit. Princeton, NJ: Princeton University Press. doi:10.1515/9781400822836

Carlsson, J., Wängqvist, M., \& Frisén, A. (2015). Identity development in the late twenties: A never ending story. Developmental Psychology, 51, 334-345.

Cole, E.R. (2009). Intersectionality and research in psychology. American Psychologist, 64, 170-180. doi:10.1037/a0014564

Côté, J.E. (2014). The dangerous myth of emerging adulthood: An evidence-based critique of a flawed developmental theory. Applied Developmental Science, 18, 177-188. doi:10.1080/10888691.2014.95 4451

Frisén, A., Carlsson, J., \& Wängqvist, M. (2014). “Doesn't everyone want that? It's just a given”: Swedish emerging adults' expectations on future parenthood and work/family priorities. Journal of Adolescent Research, 29, 67-88. doi:10.1177/0743558413502537

Furstenberg, F. (2016). Social class and development in early adulthood: Some unsettled issues. Emerging Adulthood, 4, 236-238. doi:10.1177/2167696815625142

Habermas, T., \& Reese, E. (2015). Getting a life takes time: The development of the life story in adolescence, its precursors and consequences. Human Development, 58, 172-201. doi:10.1159/000437245 
Hammack, P.L. (2008). Narrative and the cultural psychology of identity. Personality and Social Psychology Review, 12, 222-247. doi:10.1177/1088868308316892

Hammack, P.L. (2011). Narrative and the politics of identity: The cultural psychology of Israeli and Palestinian youth. New York, NY: Oxford University Press.

Hendry, L.B., \& Kloep, M. (2007). Conceptualizing emerging adulthood: Inspecting the emperor's new clothes? Child Development Perspectives, 1, 74-79. doi:10.1111/j.1750-8606.2007.00017.x

Hochschild, J.L. (1996). Facing up to the American dream: Race, class, and the soul of the nation. Princeton, NJ: Princeton University Press. doi:10.1515/9781400821730

McAdams, D.P. (2006). The redemptive self: Stories Americans live by. New York, NY: Oxford University Press. doi:10.1093/acprof:oso/9780195176933.001.0001

McLean, K.C., \& Syed, M. (2015). Personal, master, and alternative narratives: An integrative framework for understanding identity development in context. Human Development, 58, 318-349. doi:10.1159/000445817

Meeussen, L., Veldman, J., \& Van Laar, C. (2016). Combining gender, work, and family identities: The cross-over and spill-over of gender norms into young adults' work and family aspirations. Frontiers in Psychology, 7, 1781. doi:10.3389/fpsyg.2016.01781

Mitchell, L.L., \& Syed, M. (2015). Does college matter for emerging adulthood? Comparing developmental trajectories of educational groups. Journal of Youth and Adolescence, 44, 2012-2027. doi:10.1007/ s10964-015-0330-0

National Center for Education Statistics (2016). EDFacts data groups 695 and 696, school year 2014-15. Retrieved September 15, 2016.

Natsuaki, M.N., Samuels, D., \& Leve, L.D. (2015). Puberty, identity, and context. In K.C. McLean \& M. Syed (Eds.), The Oxford handbook of identity development. New York, NY: Oxford University Press.

Neugarten, B.L. (1968). Middle age and aging: A reader in social psychology. Chicago, IL: University of Chicago Press.

Rubin, D.C., \& Berntsen, D. (2003). Life scripts help to maintain autobiographical memories of highly positive, but not highly negative, events. Memory \& Cognition, 31, 1-14. doi:10.3758/BF03196077

Schulenberg, J.E., Maggs, J.L., \& O'Malley, P.M. (2003). How and why the understanding of developmental continuity and discontinuity is important. In J.T. Mortimer \& M.J. Shanahan (Eds.), Handbook of the life course (pp. 413-436). New York, NY: Kluwer Academic/Plenum Publishers. doi:10.1007/978-0-306-48247-2 19

Silva, J.M. (2016). High hopes and hidden inequalities: How social class shapes pathways to adulthood. Emerging Adulthood, 4, 239-241. doi:10.1177/2167696815620965.

Sontag, S. (2002, September 10). Real battles and empty metaphors. The New York Times, A31.

Syed, M. (2015). Emerging adulthood: Theory, developmental stage, or nonsense? In J.J. Arnett (Ed.), The Oxford handbook of emerging adulthood (pp. 11-25). New York, NY: Oxford University Press.

Syed, M., \& McLean, K.C. (2015). The future of identity development research: Reflections, tensions, and challenges. In K.C. McLean \& M. Syed (Eds.), The Oxford handbook of identity development. New York, NY: Oxford University Press.

Syed, M., \& Mitchell, L.L. (2013). Race, ethnicity, and emerging adulthood: Retrospect and prospects. Emerging Adulthood, 1, 83-95. doi:10.1177/2167696813480503

Thorne, A., \& McLean, K.C. (2003). Telling traumatic events in adolescence: A study of master narrative positioning. In R. Fivush \& C. Haden (Eds.), Autobiographical memory and the construction of a narrative self: Developmental and cultural perspectives (pp. 169-185). Mahwah, NJ: Erlbaum. 